\title{
The Utilization of Partial Orchiectomy in Treating Small Testicular Tumors in the United States
}

\author{
Shaheen Alanee ${ }^{1 *}$, Joseph Clemons ${ }^{2}$, Bradley Holland², Max Nutt ${ }^{2}$ and Danuta Dynda ${ }^{2}$ \\ ${ }^{1}$ Vattikuti Urology Institute, Henry Ford Health System, Detroit, Michigan, USA \\ ${ }^{2}$ Southern Illinois University School of Medicine, Springfield, Illinois, USA
}

*Corresponding author: Shaheen Alanee, Senior Staff Physician, Urologic Oncology, Department of Urology, Vattikuti Urology Institute, Henry Ford Health System, Detroit, Michigan, USA, Tel: 313-916-4535, Fax: 313-916-9539, E-mail: salanee1@hfhs.org

\begin{abstract}
Introduction and objectives: There is increasing evidence supporting the feasibility of Partial Orchiectomy (PO) as a treatment for small testicular tumors. However, the prevalence of this practice is still unknown. We used the Surveillance, Epidemiology, and End Results (SEER) registry to characterize national practice patterns for surgical management of patients with testicular tumors $\leq 2 \mathrm{~cm}$ in size, and we examined factors that determined performing $\mathrm{PO}$ in such patients.
\end{abstract}

Materials and methods: 32,211 patients with testicular tumors diagnosed between 1995 and 2011 were extracted for this analysis. The proportions of patients diagnosed with small tumors $(\leq 2 \mathrm{~cm})$ and patients treated with PO were determined. Trends were examined using joinpoint analysis and quantified using the Annual Percentage Change (APC). Multivariate survival models were developed to identify independent determinants of PO. Kaplan Meier analysis was used to examine the effect of PO on Cancer Specific Survival (CSS).

Results: Of the 5,365 patients with small testicular tumors and identifiable surgical treatment, only 114 patients $(2.21 \%)$ were treated with $\mathrm{PO}$. The percentage of patients diagnosed with small testicular tumors (on average $18.5 \%$ of all testis tumor patients) was stable over the study period (APC $-0.47 \%, 95 \% \mathrm{Cl}:-0.3-1.3 \%, \mathrm{P}=0.2$ ), while the utilization of partial orchiectomy for these tumors remained low and did not increase (APC -11.9\%, 95\% Cl: -16.6 - (-6.9)\%, P < $0.001)$. Older age, Black race, and living in areas with lower educational level were independent determinants of lower likelihood of receiving PO (all $p$ values $<0.05$ ). Cancer specific mortality was not worse for patients treated with $\mathrm{PO}$ vs. radical orchiectomy (Log-Rank $P=0.8605)$.

Conclusions: While a significant proportion of patients are diagnosed with small testicular tumors, the utilization of PO in treating these patients remains very low. Patient characteristics influenced the chance of treatment with $\mathrm{PO}$.
A simple preliminary analysis shows no decrease in CSS with $\mathrm{PO}$ vs. $\mathrm{RO}$ in patients with testicular masses $\leq 2 \mathrm{~cm}$.

\section{Keywords}

Testis cancer, Partial orchiectomy, SEER

\section{Introduction}

Although Radical Orchiectomy (RO) remains the gold standard treatment for testicular masses, backed by accumulating evidence and experience, Partial Orchiecto$\mathrm{my}(\mathrm{PO})$ has been examined as an alternative therapy. PO has been shown to be a feasible [1] and a therapeutic option that could possibly preserve testicular function to spare patient lifelong testosterone replacement $[1,2]$. As far as cancer control, few case series have reported favorable outcomes with testis sparing surgery for small testicular tumors, prompting some urologists to call for instituting PO as a therapeutic option for selected patients $[2,3]$. However, the impact of this evidence on practice patterns remains unclear. We used a national database to characterize practice patterns for the surgical management of small testicular tumors, review its safety, and examine determinants of receiving $\mathrm{PO}$ as a treatment for these tumors.

\section{Methods}

\section{Data source}

Data were abstracted from the National Cancer Institute Surveillance, Epidemiology, and End Results (SEER) program. The SEER Program accounts for approximate-

Citation: Alanee S, Clemons J, Holland B, Nutt M, Dynda D (2017) The Utilization of Partial Orchiectomy in Treating Small Testicular Tumors in the United States. Int J Cancer Clin Res 4:084. doi.org/10.23937/23783419/1410084

Received: August 03, 2017; Accepted: October 16, 2017; Published: October 18, 2017

Copyright: (C) 2017 Alanee S, et al. This is an open-access article distributed under the terms of the Creative Commons Attribution License, which permits unrestricted use, distribution, and reproduction in any medium, provided the original author and source are credited. 
Table 1: Demograpics and disease characteristics of patients diagnosed with testicular tumors between 1995 and 2011 stratified by tumor size.

\begin{tabular}{|c|c|c|c|}
\hline Variable & Size: $\leq 2 \mathrm{~cm}$ & Size: $\geq 2 \mathrm{~cm}$ & P-Value \\
\hline \multicolumn{4}{|l|}{ Age } \\
\hline Age $\leq 45$ & $5196(85.7 \%)$ & $21588(82.6 \%)$ & $<0.0001$ \\
\hline Age $>45$ & $867(14.3 \%)$ & $4560(17.4 \%)$ & \\
\hline \multicolumn{4}{|l|}{ Race } \\
\hline White & $5682(93.75)$ & $23721(90.7 \%)$ & $<0.0001$ \\
\hline Black & $122(2.015)$ & $808(3.1 \%)$ & \\
\hline Other* & $259(4.24 \%)$ & $1619(6.2 \%)$ & \\
\hline \multicolumn{4}{|l|}{ Laterality } \\
\hline Bilateral & 105 (1.7\%) & $429(1.6 \%)$ & 0.62 \\
\hline Unilateral & $5958(98.3 \%)$ & $25728(98.4 \%)$ & \\
\hline \multicolumn{4}{|l|}{ Education } \\
\hline Counties more than $75 \%$ of the population with high school education & $4749(78.3 \%)$ & $19698(75.3 \%)$ & $<0.0001$ \\
\hline Counties with less than $75 \%$ of the population with high school education & $1314(21.7 \%)$ & $6450(24.7 \%)$ & \\
\hline \multicolumn{4}{|l|}{ Histology } \\
\hline NSGCT & $1599(26.4 \%)$ & $8783(33.6 \%)$ & $<0.0001$ \\
\hline SGCT & $3405(56.2 \%)$ & $14433(55.2 \%)$ & 0.2 \\
\hline Other & $1059(17.5 \%)$ & $2932(11.2 \%)$ & 0.3 \\
\hline Total & 6063 & 26148 & 32211 \\
\hline
\end{tabular}

*American Indian/AK Native, Asian/Pacific Islander, and unknown.

ly $28 \%$ of the US population [4]. Patient and disease characteristics from the SEER registry are generally considered representative of the entire United States population [5].

\section{Identification of testis tumor cases}

Eligible subjects were abstracted for the diagnosis years 1995-2011. Test is cancer cases were identified using the International Classification of Disease-Oncology 3 code C62.9. Next, we retained only those patients with tumors confined to the testicle that were equal to or smaller than $2 \mathrm{~cm}$ in size.

\section{Definition of variables and interventions}

Patient and disease characteristics including age at diagnosis, race, and year of diagnosis, geographic region of treatment (SEER site), tumor histology, and tumor laterality were abstracted from SEER. Socioeconomic status was approximated by looking at percentage of residents in a county with less than high school education. For analytic purposes, each of these factors was treated as a categorical variable. Treatment classification was done using SEER variable "SEER site specific surgery", where patients classified as receiving PO included those under SEER site specific surgery code 30 , and patients classified as receiving RO included those under SEER site specific surgery codes $50,60,70,80$. This variable was chosen because previous research validated its utility as an indicator of cancer specific surgery in other genitourinary cancers [6].

\section{Statistical analysis}

The association of tumor size ( $>2 \mathrm{~cm}$ vs. $\leq 2 \mathrm{~cm}$ ) with age, race, tumor histology and educational level was examined using simple chi-square analysis. Similar analysis was done for the association between type of sur- gery ( $\mathrm{RO}$ vs. $\mathrm{PO}$ ) and these variables. Temporal trends of proportion of patients diagnosed with small testicular tumors, and patients with small testicular tumors treated with PO were assessed using join point regression, which involves fitting a series of joined straight lines on a logarithmic scale to the trends in the annual age adjusted rates, and quantified using the Annual Percent Change (APC). Temporal trend for performing PO was examined for the period of 1998-2010 because data on PO was not reliably available for earlier years or for the last part of 2011. Logistic regression analysis was used to investigate the determinants of receiving PO. Tumor histology was not included in this analysis as the decision to perform surgery in testicular cancer is almost always made with no advanced information about tumor histology. Assessment of the independent effect of surgical technique on cancer specific mortality was examined using a Kaplan Meier curve. All statistical tests were two-sided, with a significance level set at 0.05 . SEER*Stat 8.1.5, Join point 4.1.1.1, and SAS 9.4 were used for the analysis.

\section{Results}

Using SEER data from 1995 to 2011, we identified 32,211 patients treated surgically for testicular tumors, with 6,063 presenting with testicular tumors $\leq 2 \mathrm{~cm}$ in size. During this interval, 5,365 patients had identifiable surgical treatment in their SEER record, with 114 patients $(2.21 \%)$ undergoing PO. Patient and disease characteristics of patients presenting with tumors $>2 \mathrm{~cm}$ vs. $\leq 2 \mathrm{~cm}$ in size, and patients undergoing PO vs. RO are shown in Table 1 and Table 2.

Temporal trends in the diagnosis of testicular tumors $\leq 2 \mathrm{~cm}$ in size are illustrated in Figure $1 \mathrm{a}$ and Figure $1 \mathrm{~b}$. On average, close to $18.5 \%$ of testicular tumors diag- 
Table 2: Demographics of disease characteristics of patients diagnosed with small testicular tumors $(\leq 2 \mathrm{~cm})$ stratified by treatment type (Partial orchiectomy vs. radical orchiectomy).

\begin{tabular}{|c|c|c|c|}
\hline Variable & Radical orchiectomy & Partial orchiectomy & P-Value \\
\hline \multicolumn{4}{|c|}{ : } \\
\hline Age $\leq 45$ & $4502(85.7 \%)$ & $99(35.1 \%)$ & 0.7 \\
\hline Age $>45$ & $749(14.3 \%)$ & $15(13.2 \%)$ & \\
\hline \multicolumn{4}{|l|}{ Race } \\
\hline White & $4921(93.7 \%)$ & $105(92.1 \%)$ & 0.5 \\
\hline Black & $101(1.9 \%)$ & $1(0.9 \%)$ & 0.4 \\
\hline Other* & $229(4.3 \%)$ & $8(7 \%)$ & 0.07 \\
\hline \multicolumn{4}{|l|}{ Laterality } \\
\hline Bilateral & $9(0.2 \%)$ & 0 & 0.8 \\
\hline Unilateral & $5242(99.8 \%)$ & $114(100 \%)$ & \\
\hline \multicolumn{4}{|l|}{ Education } \\
\hline Counties more than $75 \%$ of the population with high school education & $4119(78.4 \%)$ & $96(84.2 \%)$ & 0.07 \\
\hline Counties with less than $75 \%$ of the population with high school education & $1132(21.6 \%)$ & $18(15.8 \%)$ & \\
\hline Total & 5251 & 114 & 5365 \\
\hline
\end{tabular}

*American Indian/AK Native, Asian/Pacific Islander, and unknown.

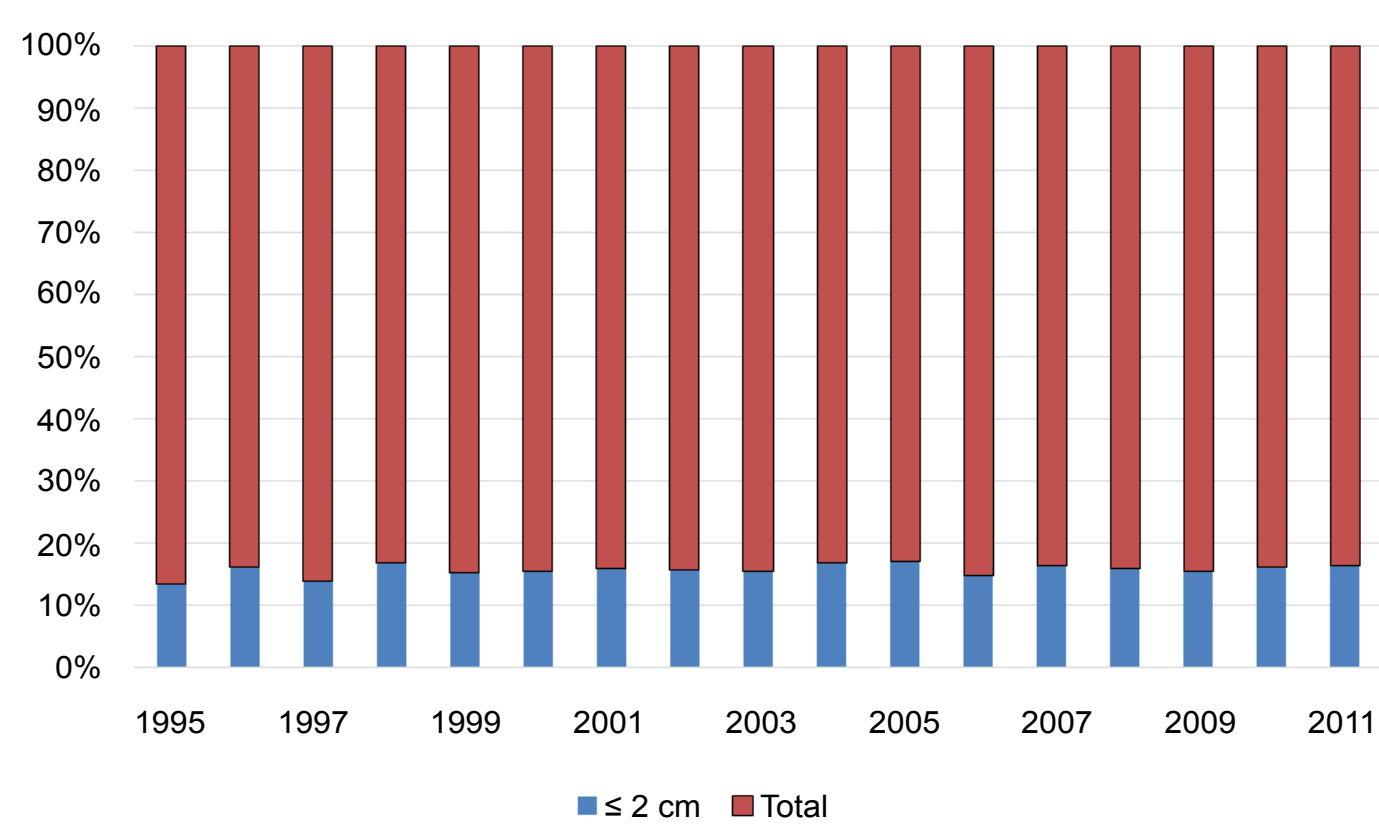

Figure 1a: Proportion of patients diagnosed with testicular tumors $\leq 2 \mathrm{~cm}$ in size in the Surveillance, Epidemiology, and End results database 1995-2011.

Table 3: Results of logistic regression analysis for the association between different patient and disease characteristics and the likelihood of treatment with partial orcheictomy in patients with testicular tumors $\leq 2 \mathrm{~cm}$ in size.

\begin{tabular}{|l|l|l|l|}
\hline Variable & \multicolumn{1}{l|}{ Odds ratio } & \multicolumn{2}{l|}{$\begin{array}{l}\text { 95\% confidence } \\
\text { limits }\end{array}$} \\
\hline Age $>$ 45 years vs. age $\leq 45$ years & 0.852 & 0.841 & 0.863 \\
\hline Black vs. white race & 0.471 & 0.451 & 0.491 \\
\hline Single side vs. bilateral tumors & 0.974 & 0.970 & 0.978 \\
\hline $\begin{array}{l}\text { Living in counties with less than 75\% of the population with high school education vs. } \\
\text { Living in counties with more than 75\% of the population with high school education }\end{array}$ & 0.785 & 0.776 & 0.793 \\
\hline
\end{tabular}

nosed between 1995 and 2011 were $\leq 2 \mathrm{~cm}$. The absence of a significant increase in the diagnosis of small testicular tumors with time is further evident in stable APC analysis (APC $-0.47 \%, 95 \% \mathrm{Cl}:-0.3-1.3 \%, \mathrm{P}=0.2$ ). Temporal trends in the utilization of $\mathrm{PO}$ in treating patients with testicular tumors $\leq 2 \mathrm{~cm}$ in size are illustrated in Figure $2 \mathrm{a}$ and Figure $2 \mathrm{~b}$. On average, $2.5 \%$ of patients with small testicular tumors were treated with PO. How- ever, the APC of treating small testicular tumors with PO showed a significant downtrend in the period of 19982010 (APC -11.9\%, 95\% Cl: -16.6 - (-6.9)\%, P < 0.001).

The final adjusted model demonstrating the independent association between various pretreatment patient and tumor characteristics and PO use is summarized in Table 3. Age greater than 45 (Hazard Ratio (HR): 0.852, 95\% Cl: 0.841-0.863, $\mathrm{P}<0.0001$ ), Black race (HR: 0.471, 


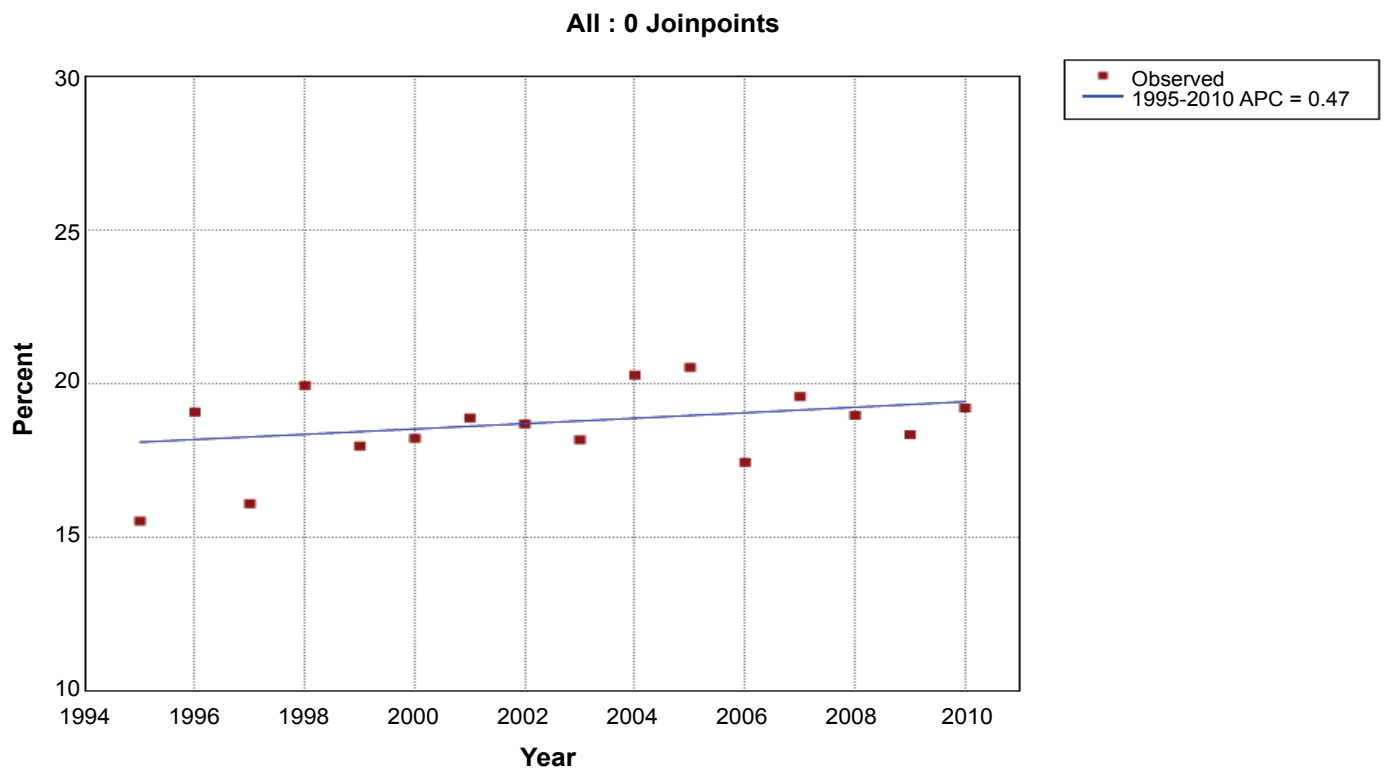

Figure 1b: Annual percentage change in proportion of patients diagnosed with testicular tumors $\leq 2 \mathrm{~cm}$ in size in the Surveillance, Epidemiology, and End results database 1995-2011.

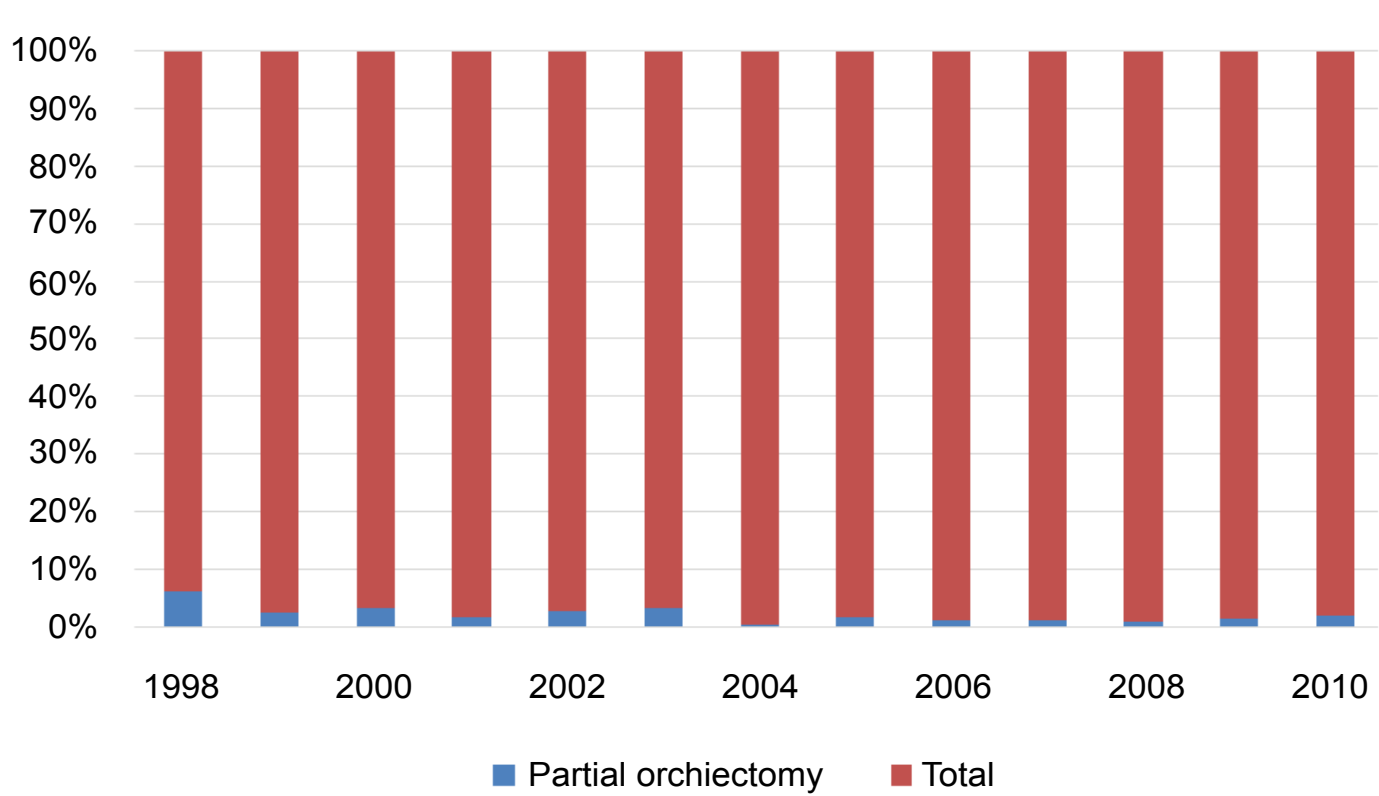

Figure 2a: Proportion of patients with testicular tumors $\leq 2 \mathrm{~cm}$ in size treated with partial orchiectomy in the Surveillance, Epidemiology, and End results database 1998-2011.

95\% Cl: 0.452-0.491, $\mathrm{P}<0.0001)$, and lower education level (HR: $0.785,95 \% \mathrm{Cl}: 0.776-0.793, \mathrm{P}<0.0001$ ) were all independent determinants of decreased $\mathrm{PO}$ use in treating small testicular tumors in this analysis.

Finally, Kaplan Meier analysis did not show a significant difference in the HR of dying from testicular cancer in patients treated with $\mathrm{PO}$ vs. those treated with RO (P $=0.8605$ ) (Figure 3).

\section{Discussion}

While PO has been suggested to be a possible treatment for small testicular masses [1-3], its safety as a cancer control surgery remains to be validated $[7,8]$, and its utilization in everyday urology practice has not been ex- amined. In this population based study, a significant proportion of patients diagnosed with testicular tumors had lesions that fit the criteria for organ-sparing surgery $1 \leq 2$ $\mathrm{cm}$ in size), but the use of PO continues to be very limited. In fact, our numbers show a downward trend in PO utilization for the treatment of testicular tumors that is probably related to adding more registries to SEER in the early 2000 s. Urologists may be justified in treating most testicular tumors with radical orchiectomy because of the high incidence of associated Carcinoma In Situ (CIS) [9], and the poor compliance of patients with follow-up [10]. However, our observations support the need for a reconsideration of $\mathrm{PO}$ in treating patients with testicular tumor since it is hard to accept that only $2.21 \%$ of patients with small testicular tumors are fit for such treatment. 


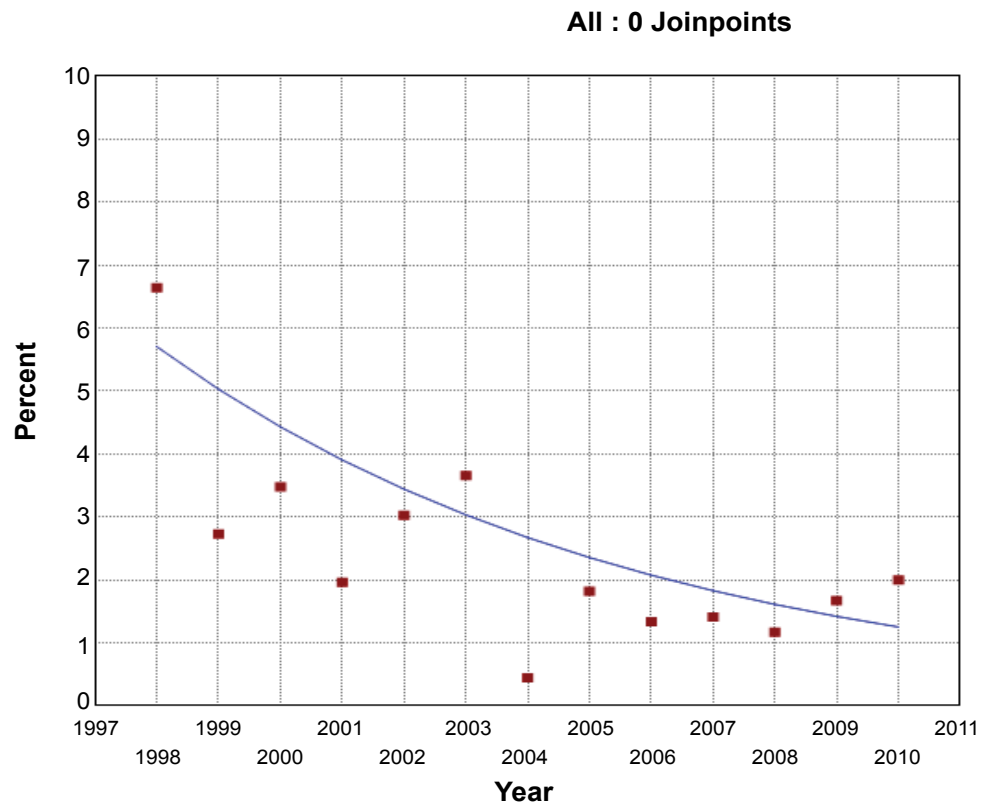

Observed $1998-2010$ APC $=-11.86^{\wedge}$

Figure 2b: Annual percentage change in the proportion of patients diagnosed with testicular tumors $\leq 2 \mathrm{~cm}$ in size treated with partial orchiectomy in the Surveillance, Epidemiology, and End results database 1998-2011.

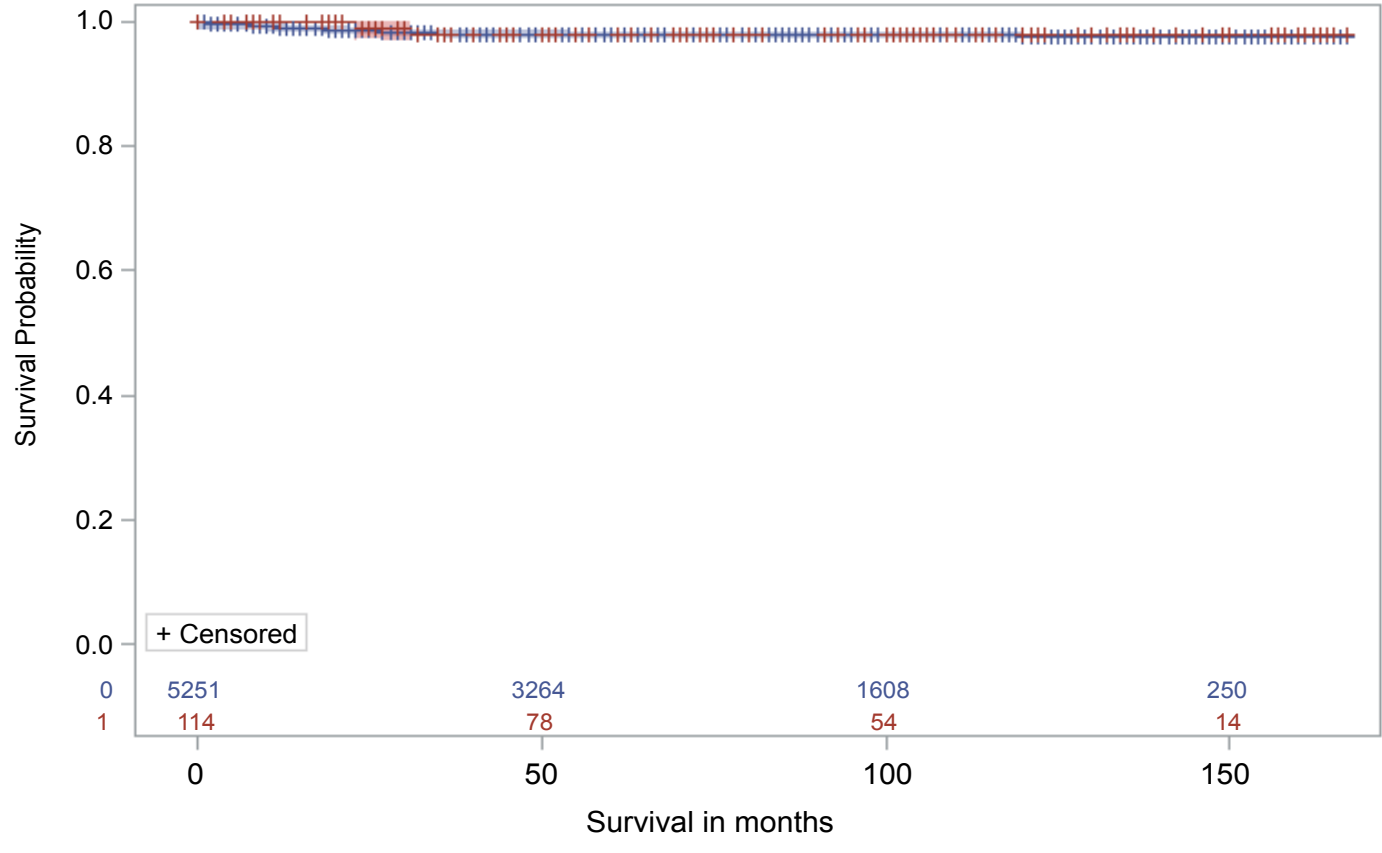

Partial orchiectomy $\quad$ No $\longrightarrow$ YES

Figure 3: Kaplan-Meier curve for cancer specific survival of patients treated with partial orcheciotomy vs. radical orchiectomy for testicular tumors $\leq 2 \mathrm{~cm}$ in size.

It is also interesting to observe age, race and education differences in the likelihood of receiving PO. In particular, black patients were much less likely to be treated with PO than white patients. Racial differences in utilization of more advanced treatment options are well documented [11], but this is the first time such differences are reported in localized treatment of testicular tumors. Our results also show that patients from areas with lower educational levels are less likely to be treated with PO. This finding is also not surprising because socioeconomic disparities in the utilization of healthcare services are also well recognized [12]; the lower likelihood of receiving PO with older age, however, lacks an appropriate justification. Older males are at a higher risk of underlying endocrine deficiency [13], and if the main benefit of PO was to preserve testosterone production, then older patients should be the focus of this treatment. Preserving as much testicular tissue as possible in older males may be important considering that age-related decline in gonadal function may be compounding the effects of the possible underlying Leydig cell dysfunction in patients with testicular 
cancer. In a study by Willemse, et al., the authors assessed the serum values of testosterone and gonadotropic hormones in patients undergoing orchiectomy for cancer or benign entities. They then found that Luteinizing Hormone (LH) levels were equally elevated in all patients, but the testosterone levels were decreased only in patients treated with orchiectomy for testicular cancer [14]. In another study, Jacobsen, et al. examined gonadal function in 63 patients with bilateral testicular cancer after their first orchiectomy, and compared the results with those from 174 patients with unilateral testicular cancer after orchiectomy. They found LH levels to be significantly elevated in patients who subsequently developed a second primary tumor in the contralateral testis [15]. While compelling, these studies are not enough to definitively answer the question of whether testicular cancer is associated with global Leydig cell loss of function. However, it would be interesting to investigate whether the risk of hypogonadism is included in urologists' discussions of surgical treatment with their older testis tumor patients, and if such discussion could contribute to a higher utilization of $\mathrm{PO}$ in older males seen in urology clinic.

Our study shows, through a preliminary analysis that, as far as cancer control goes, PO is not inferior to RO. This finding is in line with previous case series showing safety of PO in carefully selected patients $[2,3]$. It is also in line with the proven efficacy of organ sparing surgery in selected patients with other genitourinary malignancies [16]. The main concern with oncologic efficacy of $\mathrm{PO}$ is the high prevalence of CIS in the testicular tissue surrounding the tumors [9]. In fact, the German Testicular Cancer Study Group reported on 4 patients (5.4\%) with local recurrence diagnosed by periodic scrotal sonography after PO. Detailed analysis revealed that 3 of the 4 had CIS in the residual testicular parenchyma and had not been treated with adjuvant RT. All 4 patients underwent secondary testicular ablation and were without evidence of disease at their last follow-up visit. Therefore, adjuvant testicular RT of the retained testis is recommended to obtain durable recurrence-free survival [2].

There are several limitations to this study. First, SEER data does not include data on tumor location (central vs. peripheral), making it hard to speculate on percentage of patients with small testicular tumors who were not very good candidate for $\mathrm{PO}$ because procedure complexity. Second, SEER data does not include any information about whether PO was discussed with patients in clinic making it impossible to account for patient's choice of treatment in the analysis. Third, SEER does not include any data on endocrine function preventing us from studying preserving testosterone production as an outcome of PO. Fourth, SEER does not provide information about patient's history of previous orchiectomy, or congenital malformation/surgery/injury on the contralateral testis. Knowledge about these preexisting conditions that would lead to decreased function of the contralateral testis is important because they may affect the urologist's decision to recommend PO vs. RO. Despite these limitations, our data provides nationally representative estimates of PO use for testicular masses $\leq 2 \mathrm{~cm}$ in size, and provides insight regarding the determinants of $\mathrm{PO}$ in this patient population.

\section{Acknowledgements}

None.

\section{Ethical Standards}

The manuscript does not contain clinical studies or identifiable patient data.

\section{Conflict of Interest}

The authors declare that they have no conflict of interest.

\section{References}

1. Weissbach $L$ (1995) Organ preserving surgery of malignant germ cell tumors. J Urol 153: 90-93

2. Heidenreich A, Weissbach L, Höltl W, Albers $P$, Kliesch $S$, et al. (2001) Organ sparing surgery for malignant germ cell tumor of the testis. J Urol 166: 2161-2165.

3. Heidenreich A, Höltl W, Albrecht W, Pont J, Engelmann UH (1997) Testis-preserving surgery in bilateral testicular germ cell tumours. Br J Urol 79: 253-257.

4. Ueda M, Kudo T, Kuge Y, Mukai T, Tanaka S, et al. (2010) Rapid detection of hypoxia-inducible factor-1-active tumours: pretargeted imaging with a protein degrading in a mechanism similar to hypoxia-inducible factor-1alpha. Eur J Nucl Med Mol Imaging 37: 1566-1574.

5. Hankey BF, Ries LA, Edwards BK (1999) The surveillance, epidemiology, and end results program: a national resource. Cancer Epidemiol Biomarkers Prev 8: 1117-1121.

6. Hollenbeck BK, Taub DA, Miller DC, Dunn RL, Wei JT (2006) Use of nephrectomy at select medical centers--a case of follow the crowd? J Urol 175: 670-674.

7. Bazzi WM, Raheem OA, Stroup SP, Kane CJ, Derweesh $\mathrm{IH}$, et al. (2011) Partial orchiectomy and testis intratubular germ cell neoplasia: World literature review. Urol Ann 3: 115-118.

8. Yossepowitch O, Baniel J (2004) Role of organ-sparing surgery in germ cell tumors of the testis. Urology 63: 421-427.

9. Dieckmann KP, Skakkebaek NE (1999) Carcinoma in situ of the testis: review of biological and clinical features. Int $J$ Cancer 83: 815-822.

10. Moynihan C, Norman AR, Barbachano Y, Burchell L, Huddart R, et al. (2009) Prospective study of factors predicting adherence to medical advice in men with testicular cancer. J Clin Oncol 27: 2144-2150.

11. Kates M, Whalen MJ, Badalato GM, McKiernan JM (2013) The effect of race and gender on the surgical management of the small renal mass. Urol Oncol 31: 1794-1799.

12. Becker A, Roghmann F, Trinh QD, Hansen J, Tian Z, et al. (2013) Sociodemographic disparities in the treatment of small renal masses. BJU Int 111: E274-E282.

13. Golan R, Scovell JM, Ramasamy R (2015) Age-related tes- 
tosterone decline is due to waning of both testicular and hypothalamic-pituitary function. Aging Male 18: 201-204.

14. Willemse PH, Sleijfer DT, Sluiter WJ, Schraffordt Koops H, Doorenbos H (1983) Altered Leydig cell function in patients with testicular cancer: evidence for bilateral testicular defect. Acta Endocrinol (Copenh) 102: 616-624.
15. Jacobsen KD, Fosså SD, Bjøro TP, Aass N, Heilo A, et al. (2002) Gonadal function and fertility in patients with bilateral testicular germ cell malignancy. Eur Urol 42: 229-238.

16. Campbell SC, Novick AC, Belldegrun A, Blute ML, Chow GK, et al. (2009) Guideline for management of the clinical T1 renal mass. J Urol 182: 1271-1279. 